\title{
Do we need to reassess the meaning of "team" in our health care environments?
}

The views expressed in this editorial are those of the author and do not necessarily reflect the position of the Canadian Medical Association or its subsidiaries.

T he use of the word "team" has become ubiquitous in health care and in life. Irrespective of the number of members or tasks at hand, it seems that most groups within our daily environment are now suffixed with the term. Although most of us don't frequently stop to consider its superfluous use, the word "team" has traditionally held an incredibly important meaning within our collective psyche. While the definition varies depending on the source, many people immediately contemplate the sporting arena and define a team as a group of people who perform interdependent tasks to work toward a specific objective (e.g., winning a championship). What is missing in this concept, however, is the underlying assumption that individual members of the group often engage in uncomfortable yet productive tasks for the benefit of the larger group and their collective mission. This component is critical to separating true teams from those who simply apply the moniker to a given group.

What clearly differs among teams, however, are the repercussions of endorsing a given individual challenge in pursuit of a group's common mission. This may range from performing a task in an uncomfortable environment (e.g., volunteerism) to physical discomfort/accountability (e.g., contact sports) to the ultimate sacrifice (e.g., military operators). Musicians frequently carry an interesting definition of "team" that incorporates the core meaning of being the member of a band - more specifically, the ability to play individual instruments in unison, while forgoing the pleasure and glory of a solo piece. In the context of a team, the details of the sacrifice can vary, but the concept of completing a task that is required for group success, and without personal gain, is essential.

In the arena of health care, we apply the word "team" to a myriad of tasks and groups that fail to meet these core definitional components. Being salaried to place intravenous catheters into patients over the course of a shift, for example, does not meet the requirement bar for an "IV team." The nuance within these comparisons may seem trivial, but the difference between "team" and "group" is as important as the operational disparity between the terms "leader" and "manager."

As one would expect, some of our most revered leaders have deeply explored the intricate requirements and components of the team concept. Tom Coughlin, Super Bowlwinning coach and executive, offers that team success demands individual struggle. Members who are given individual exemptions within a team context become selfish and insensitive to the real values of the team. He argues that the very nature of the hard individual work and sacrifice (that some team members try to avoid) remains a critical building block for the foundational development of a successful team. More specifically, he says "it's not about rights and privileges of any individual member. It's about obligations and responsibilities. And the question is: Can we count on you? Doing the right things the right way all the time (as the team has laid out) is necessary because we are what we repeatedly do." In other words, team excellence is not an act, but a habit. He further states that "personal discipline, organization of your priorities, and committing yourself to the task without shortcut or procrastination" is your role as an individual member of a productive team.

Perhaps the best example of a team is New Zealand's national rugby team, the All Blacks. "Sweep the sheds" is a moniker for this team that has become a neo-religion. On the surface, this sentiment appears to reflect the importance of maintaining a spotless pro-sports locker room. But at its core, it comments on the reality that team members must engage in the task of making the locker room shine, despite its unpleasant nature. In other words, no one within the team, irrespective of talent or title, is too big to do the small things that need to be done (i.e., cleaning up after himself, and others, in this instance). This concept is worthy of consideration within our operating rooms, whether it comes to helping move the patients from the operating table to the stretcher, assisting with room changeovers, or even acknowledging all team members cleaners, porters, etc. - by name.

We know that the composition of all teams is critically important. ${ }^{2}$ More specifically, it is clear (both by experience and with reproducible mathematics) that diversity within teams themselves leads to a measureable and predictable improvement in outcomes. ${ }^{3}$ As a result, it is incumbent upon our health care leadership to construct teams with the optimal mix of diversity, discipline, selfaccountability, experience, creativity and selflessness that offers the best chance of successfully achieving the team's collective goal. One also wonders what effect competency by design surgical training may have on trainees working individually for extended periods. Could this lead to 
competent solo individuals composing incompetent teams? $?^{4}$ Perhaps the final concept to think about in the context of the term "team" is the reality that all successful teams have a defined lifespan. More to the point, teams must be infused with new blood, fresh ideas, reorganization and a re-evaluation of the core mission that is repeatedly stated for the collective. Sometimes this is as simple as revisiting traditional rallying cries (e.g., the haka ritual in the case of the All Blacks, https://www.youtube.com/ watch?v=yiKFYTFJ_kw) or as complex as a complete overhaul of group culture and leadership. This process of renewal, however, must engage all team members; not just those who have an administrative title. Buy-in from the entirety of the group remains the core of any hopeful elevation to meeting the true definition of a team.

\section{Chad G. Ball, MD, MSc; Edward J. Harvey, MDCM, MSc;} Melinda Davis, BMed

Affiliations: Coeditors in chief, Canadian fournal of Surgery (Ball, Harvey); the Department of Surgery, University of Calgary, Calgary, Alta. (Ball); the Department of Surgery, McGill University, Montreal, Que.(Harvey); and the Department of Anesthesiology, University of Calgary, Calgary, Alta. (Davis).

Competing interests: E.J. Harvey is the chief medical officer of Greybox Solutions, the co-founder and head of medical innovation of NXTSens Inc., the co-founder and chief medical officer of MY01 Inc., and the co-founder and director of Strathera Inc. He receives institutional support from J \& J DePuy Synthes, Stryker and Zimmer, and he is a board member of the Orthopedic Trauma Association and the Canadian Orthopaedic Association. No other competing interests were declared.

DOI: $10.1503 /$ cjs. 022620

\section{References}

1. Kerr J. Legacy: What the All Blacks can teach us about the business of life. Constable \& Robinson LTD. 2015.

2. Coyle D. The culture code: The secrets of highly successful groups. Penguin Random House. 2017.

3. Page S. The difference: How the power of diversity creates better groups, firms, schools and societies. Princeton, NJ: Princeton University Press. 2007.

4. Lingard L. What we see and don't see when we look at 'competence': notes on a god term. Adv Health Sci Educ Theory Pract 2009;14:625-8. 